D.V. Efanov, D. Sc. (Tech.)

Federal State Autonomous Educational Institution of Higher Education

"Russian University of Transport"

(Russian Federation, 127994, Moscow, Obraztsova str., build. 9/9)

contact phone number (+7) (911) 709-2164, e-mail: TrES-4b@yandex.ru)

\title{
Fault-tolerant structures of digital devices based on Boolean complement with the calculations checking by sum codes
}

The article considers the construction of fault-tolerant digital devices and computing systems that does not use the principles of introducing modular redundancy. To correct the signals, a special distorted signal fixation unit, concurrent error-detection by the pre-selected redundant code circuit, as well as a signal correction block are used. The distorted signal fixation unit is implemented by the Boolean complement method, which makes it possible to design a large number of such blocks with different indicators of technical implementation complexity. When synthesizing a fault-tolerant device according to the proposed method, it is possible to organize a concurrent error-detection circuit for both the source device and the Boolean complement block in the structure of the distorted signal fixation unit. This makes it possible to choose among the variety of ways to implement fault-tolerant devices according to the proposed method, one that gives a device with the least structural redundancy. Various redundant codes can be used to organize concurrent error-detection circuits, including classical and modified sum codes. The author provides algorithms for the synthesis of distorted signal fixation unit and the Boolean complement block. The results of experimental researches with combinational benchmarks devices from the well-known LG'91 and MCNC Benchmarks sets are highlighted. The article presents the possibilities of the considered method for the organization of faulttolerant digital devices and computing systems.

K e y w o $r$ d s: fault-tolerant digital device; calculations checking; Boolean complement; fault-tolerant structures; double modular redundancy.

When developing modern computing devices and systems, it is necessary not only to ensure the performance of the required functions, but also to endow them with the property of detecting faults occurring in their components and errors in calculations, as well as the ability to parry them. That is why computing devices and systems often have checkable and self-checking structures,

(C) Efanov D.V., 2021 
are equipped with advanced testing and self-testing means, and are also implemented in such a way that they are insensitive to the most probable faults and errors in calculations [1-7].

The design of highly reliable digital devices and systems implies the use of the principles of reservation and diversification of hardware and software at various levels of their implementation [8-10], using methods of protecting and encoding information [11-14].

The most prevalent is the architecture based on the use of triple modular redundancy (the TMR-structure) [15-20]. The device includes three modules that calculate the similar functions on their self-titled outputs. The modules can be both identical and implemented according to different structures, this makes it possible to detect the same type of errors associated with the features of the technical implementation of devices. The self-titled outputs of three different blocks are connected to the inputs of majority devices that implement the decisive function of the majority: at the output of such an element, a value is formed corresponding to the value at the inputs that occurs the most number of times (at least two out of three) [21].

Thus, the implementation of a fault-tolerant device according to the TMRstructure requires significant redundancy. To detect a failed module in a faulttolerant device, it is necessary to arrange the concurrent error-detection (CED) circuits of the modules themselves and modify the majority elements to add the property of identifying a faulty input [22]. This leads to an even greater complication of the device and an increase in the redundancy of its structure. A fault-tolerant device implemented according to the TMR-structure has the property of fixing any faults and errors in calculations that occur in one of the modules. This feature of the TMR-structure determines its widespread use and application in many industries and transport for the implementation of responsible functions.

In a number of papers, for example, in [23, 24], it is shown that faulttolerant devices can be implemented using structures with double modular redundancy (DMR-structures). In this case, it is necessary to check the calculations of one of the modules performing identical functions, or to check the calculations at the outputs of both modules, as well as a signal comparison circuit that does not use majority elements. In this case, the technical implementation complexity of a fault-tolerant device is reduced compared to a device implemented using the TMR-structure. However, the property of detecting any faults and errors in calculations at the outputs of one module is lost.

The detecting characteristics are determined by the capabilities of the CED circuit used for calculations checking. For example, in [25], a parity code is used for calculations checking, which detects any errors at the outputs of checked devices associated with distortion of an odd number of signals; 
other errors are not detected by parity codes. There are known circuit engineering techniques that make it possible to detect any errors at the outputs of devices using the parity code [2]. However, these methods impose restrictions on the set of faults (on the fault model) that they make it possible to take into account.

In [25], a fault-tolerant structure is proposed, implemented without using the principle of modular redundancy. It assumes the presence of a specialized distorted signal fixation (DSF) unit, implemented by the Boolean complement method [26-28]. In this case, it is necessary to check the calculations either by the source device itself, or by the Boolean complement block in the DSF unit. This checking is carried out using the CED circuit, implemented by the parity code.

Let's set the task to investigate how the characteristics of structural redundancy change when other codes are used in the CED circuit, which allow detecting a much larger number of errors at the device outputs than the parity code.

It is proposed to check calculations at the outputs of modules in the faulttolerant structure based on sum codes, or $\Sigma_{m}$-codes, where $m$ is the length of the data vector. The article considers the following sum codes: classical Berger codes $\left(S_{m}\right.$-codes) [29], codes with summation of weight coefficients of pairs of bits occupying adjacent positions in data vectors, or codes with summation of weighted transitions ( $T_{m}$-codes) [30], as well as parity codes $\left(P_{m}\right.$-codes) and codes with repetition $\left(D_{m}\right.$-codes), which actually underlie the synthesis of CED circuits based on the duplication principle. The choice of these codes is not accidental. These have special properties, taking this into account makes it possible to synthesize devices with the detection of a specific type of errors at the outputs of diagnostic objects.

Fault-tolerant structures based on double modular redundancy can be implemented with the check of calculations by both modules, as well as with the check of calculations by only one of them. The second option makes it possible to simplify the error correction circuit. Let' s consider these structures in more detail.

First of all, we note that we will consider the model of stuck-at faults at the outputs of the internal gates of the device. This model covers up to 80$95 \%$ of real physical defects, depending on the technology of the device implementation [21]. It should be emphasized, however, that the binding to the fault model is conditional here, because, in fact, not the faults themselves will be detected in the structures, but their manifestations in the form of distortions of the calculation results. The detecting characteristics will be determined only by the CED circuits properties and the features of error detection by the used $\Sigma_{m}$-code. 
The source device $F(x)$ implements a system of Boolean functions $f_{1}, f_{2}, \ldots, f_{m-1}, f_{m}$. In a fault-tolerant structure, it is provided with its own copy $F^{*}(x)$, which implements the same functions. As a $F^{*}(x)$ device, not necessarily a copy of the $F(x)$ device can be used, but for example, a device implemented in a different way, but calculating exactly the same functions (this is the diversification of hardware).

To identify the outputs at which errors occur, a cascade of comparison elements is used in DMR-structures. These are elements of addition by modulo $M=2$ (XOR elements) $a_{1}, a_{2}, \ldots, a_{m-1}, a_{m}$. If an error is present at any of the $f_{1}, f_{2}, \ldots, f_{m-1}, f_{m}$ outputs of the $F(x)$ or $F^{*}(x)$ device, then an on-data value will be present at the corresponding output of the comparison element. This makes it possible to fix any single error in the calculations by both modules. To identify the device at the outputs of which an error occurred, the CED circuit implementation by the $\Sigma_{m}$-code is required. In the first case (Fig. 1, $a$ ), the CED circuit is implemented for the $F(x)$ device, and in the second case (Fig. 1, $b$ ) for the alternative device $F^{*}(x)$. The CED circuit makes it possible to fix which device has an error at the outputs, and to correct the signals only if the error occurred in the source object.

The CED circuit is implemented by the $\Sigma_{m}$-code and contains three blocks. The $H(x)$ block generates the $h_{1}, h_{2}, \ldots, h_{k-1}, h_{k}$ check bits values of the selected code by the values of the inputs. The $H(f)$ block implements the similar functions $h_{1}^{\prime}, h_{2}^{\prime}, \ldots, h_{k-1}^{\prime}, h_{k}^{\prime}$ by the $f_{1}, f_{2}, \ldots, f_{m-1}, f_{m}$ values of outputs. The values from the same outputs of the $H(x)$ and $H(f)$ blocks are compared on the XOR elements $c_{1}, c_{2}, \ldots, c_{k-1}, c_{k}$ of the comparison circuit. If an error occurs at least at one of the outputs of the $H(x)$ and $H(f)$ blocks, a single value is formed at the output of the corresponding XOR element.

To reduce the number of outputs of the comparison circuit, a Boolean addition element OR with $k$ inputs is used. An error signal is generated at its output $z$ : if $z=1$, then there is an error in the calculations, otherwise there is no error. The $z$ signal actually initiates a correction. In the structure with the calculations check by the $F(x)$ device, the output of the comparison circuit is connected directly to the inputs of the elements of the signal correction block (see Fig. 1, a). In the structure with the calculations check by the $F^{*}(x)$ device, the output of the comparison circuit is connected to the inputs of the elements of the signal correction block, but is previously inverted (see Fig. 1, b). This is necessary to avoid a false correction as a result of the $F^{*}(x)$ block failure

The signal correction block is implemented as a device with two cascades. The $1^{\text {st }}$ cascade is formed by $m$ parallel elements of the Boolean multiplication AND with two inputs. It is intended to generate a correction signal when an error is fixed. The first inputs of AND elements receive $e_{1}, e_{2}, \ldots, e_{m-1}, e_{m}$ signals from the computation comparison circuit by $F(x)$ and $F^{*}(x)$ blocks, directly 

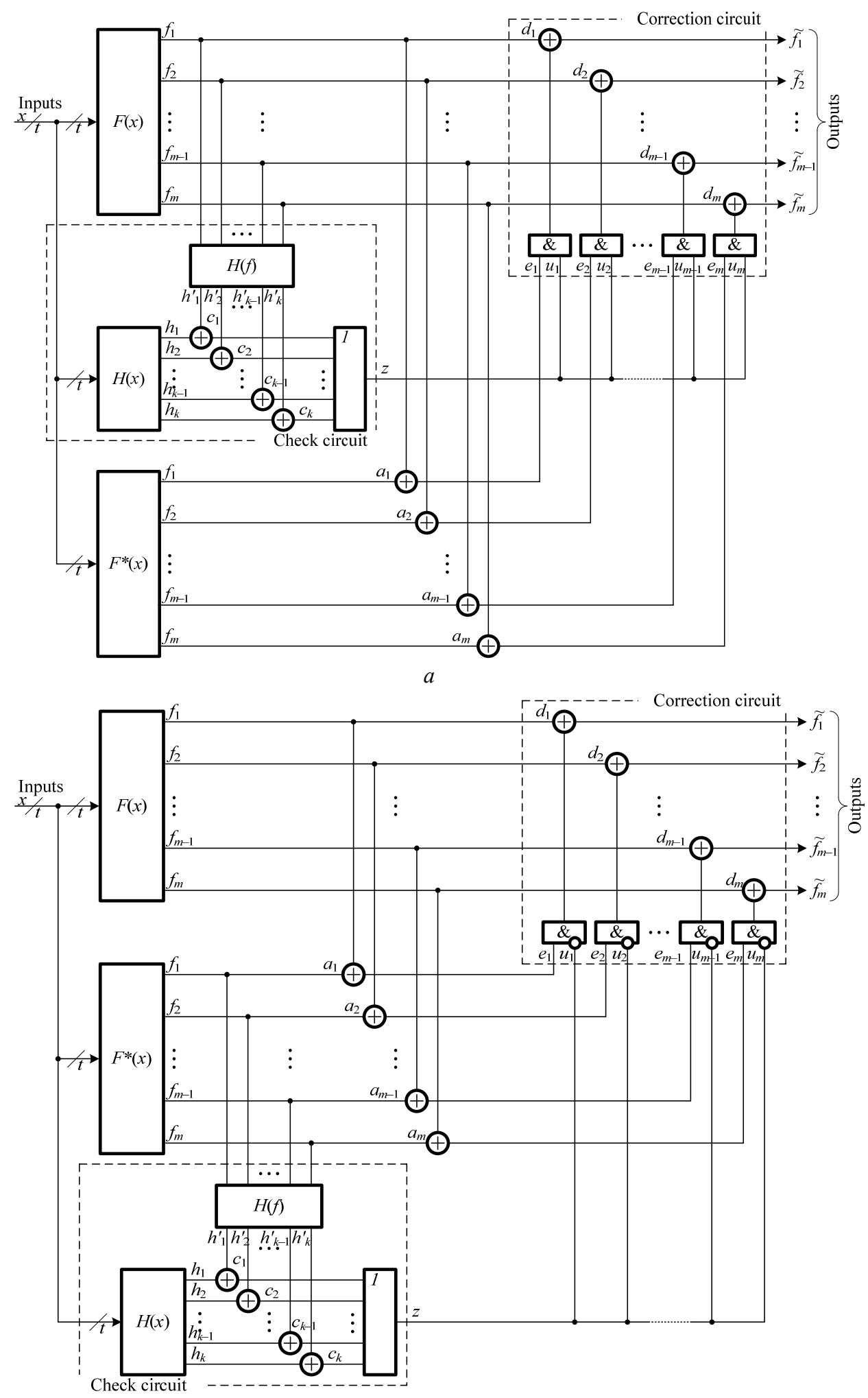

$b$

Fig. 1. The fault-tolerant device based on duplication with the calculations check by the main (a) and additional (b) devices by the $\Sigma_{m}$-code 
from the outputs of $a_{1}, a_{2}, \ldots, a_{m-1}, a_{m}$ elements. The 2 nd inputs receive $u_{1}=$ $=u_{2}=\ldots=u_{m-1}=u_{m}=z$ signals from the CED circuit. A cascade of $d_{1}, d_{2}, \ldots$ $\ldots, d_{m-1}, d_{m}$ two-input XOR elements is used in the correction block to correct errors at the outputs of the $F(x)$ block.

The structures shown in Fig. 1 are not protected from the faults of the elements of the signal correction block. The same disadvantage is inherent in the traditional TMR-structure, which does not use majority elements with fixing inputs with incorrect values [21]. In practice, this disadvantage is offset by the use of highly reliable elements in the synthesis of a signal correction block with low failure flow intensities, internal reserve and implemented in the form of totally self-checking devices [2,3].

The CED circuit is implemented by the pre-selected code, the features of which determine both the features of error detection at the outputs of the checked device and the circuit engineering techniques used to detect any errors that occur at its outputs [12-14].

Fault-tolerant structures based on Boolean complement. In [25], it is proposed to implement fault-tolerant devices without using methods of modular redundancy introducing. This approach is based on the implementation of the specialized DSF unit synthesized using the method of Boolean complement. In this case, the calculations checking possible to organize in two ways: to check the $F(x)$ block or to check the Boolean complement block in the DSF unit structure. In [25], the parity code is used for calculations checking.

Fig. 2 shows generalized structures based on the Boolean complement method with the calculations checking by $\Sigma_{m}$-codes. To determine the corrected functions in these two structures, it is assumed that the DSF unit is used, which includes the $G(x)$ Boolean complement block, the $R(x)$ block for correction functions implementation and two cascades of comparison elements: $a_{1}, a_{2}, \ldots, a_{m-1}, a_{m}$ and $b_{1}, b_{2}, \ldots, b_{m-1}, b_{m}$. The $G(x)$ Boolean complement block forms the complement functions $g_{1}, g_{2}, \ldots, g_{m-1}, g_{m}$, intended for comparison with the same-name outputs of the $F(x)$ block. The signals are compared on the XOR elements $a_{1}, a_{2}, \ldots, a_{m-1}, a_{m}$. To activate the correction, the functions $r_{1}, r_{2}, \ldots, r_{m-1}, r_{m}$, formed by the $R(x)$ block, as well as a cascade of XOR elements $b_{1}, b_{2}, \ldots, b_{m-1}, b_{m}$ are used. Error functions are formed according to the following rule: $e_{i}=f_{i} \oplus g_{i} \oplus r_{i}=0, i=\overline{1, m}$. If, as a result of a fault, the $f_{i}$ function value is distorted in the $F(x)$ block, then according to this rule, $e_{i}=1$ and the input and output of the corresponding Boolean multiplication element in the signal correction block are activated (at the same time, the CED circuit output of the $F(x)$ block $z=1)$. The incorrect $f_{i}$ function value is being corrected.

The difference between the structures shown in Fig. 2 is that in the structure shown in Fig. 2, $a$, calculations are checked by $F(x)$ block, and in the structure 


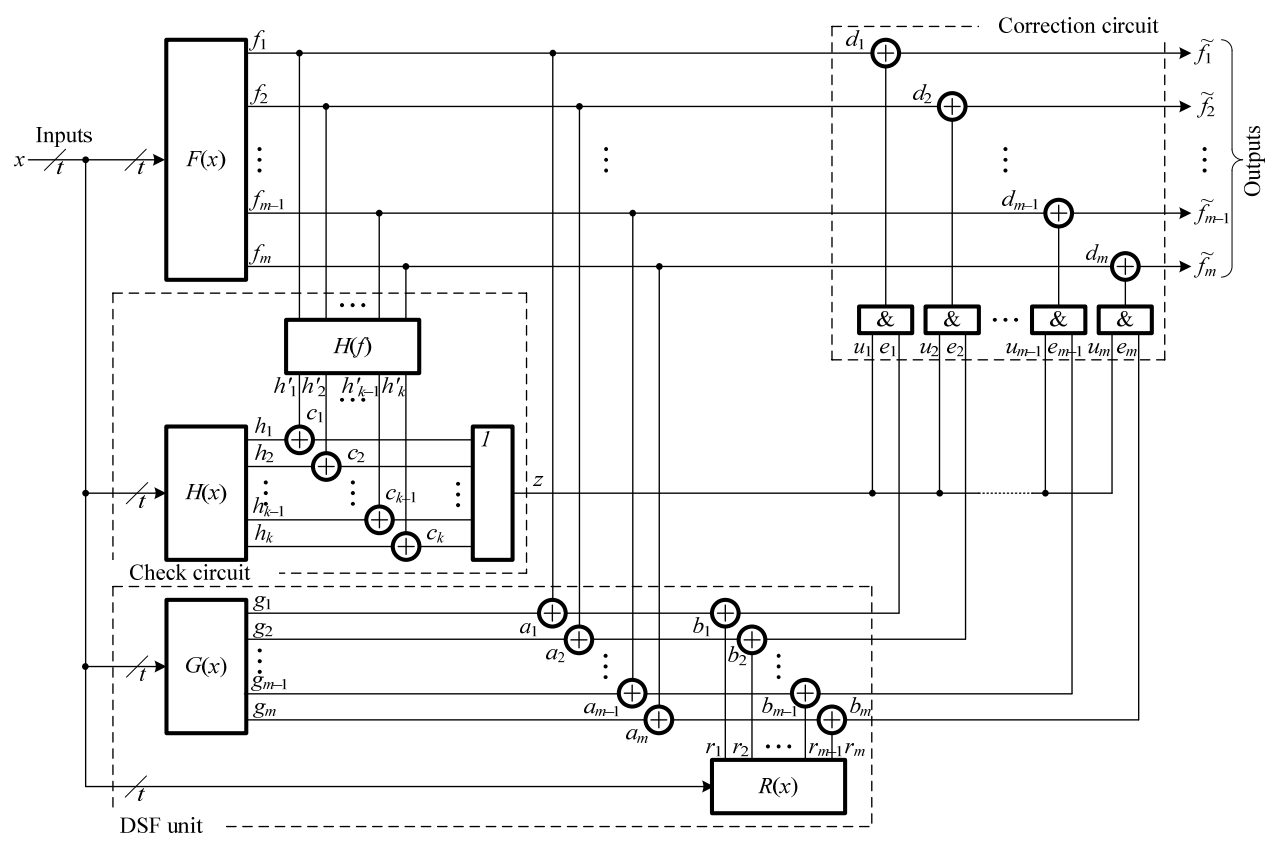

a

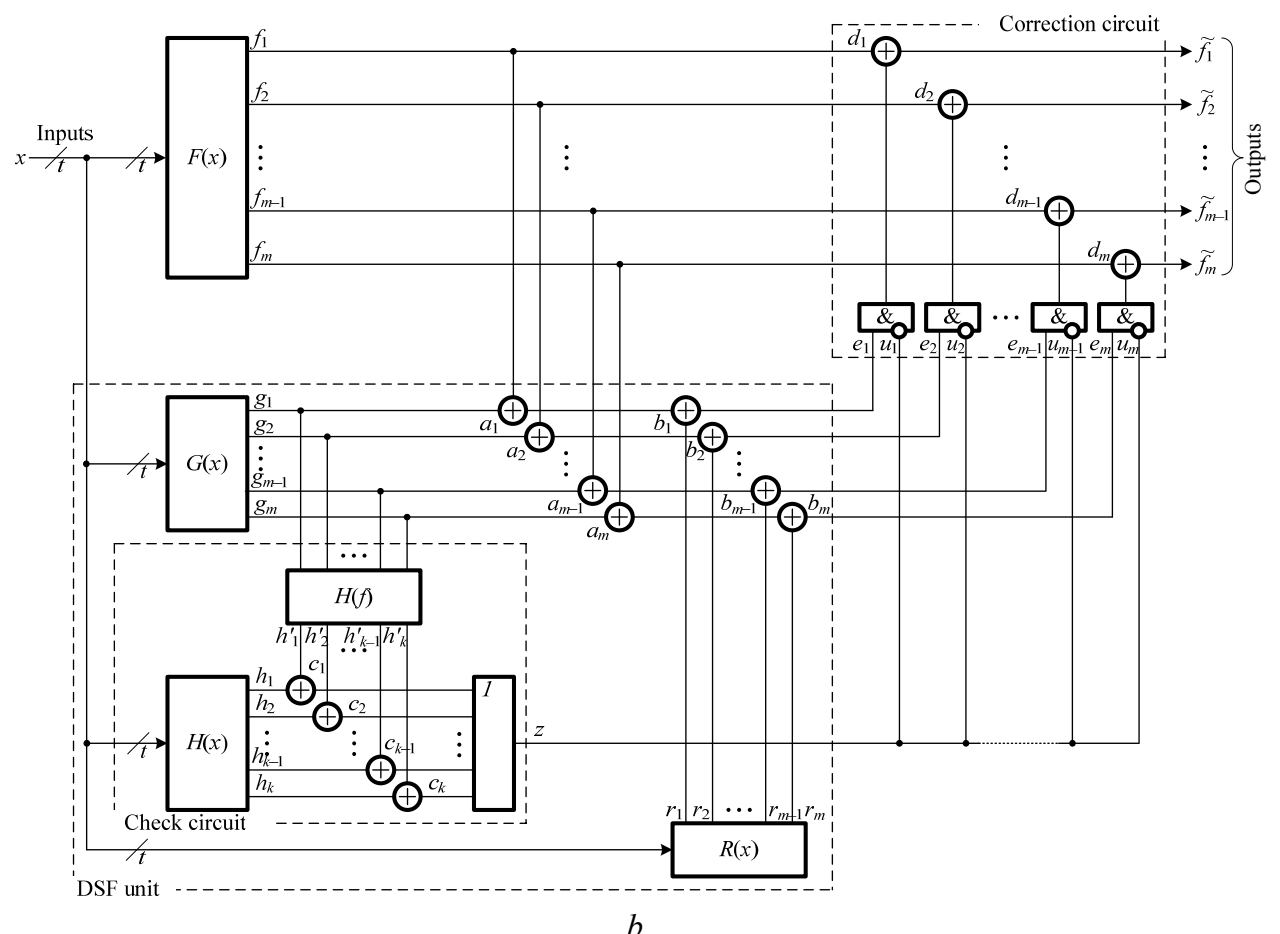

Fig. 2. The fault-tolerant device based on Boolean complement with the calculations check by the source device $(a)$ and the block of addition $(b)$ by the $\Sigma_{m}$-code 
shown in Fig. 2, $b$, calculations are checked by $G(x)$ block. The principle of operation is similar to the principle of operation of the structures shown in Fig. 1. The correction is carried out only if errors in the calculations are fixed by the $F(x)$ block. In the structure in Fig. 2, $a$, the error signal makes it possible to activate the correction, and in the structure in Fig. 2, $b$, on the contrary, when fixing the $G(x)$ error, a false correction is excluded, because the signal from the CED circuit is inverted at the inputs of the signal correction block.An important advantage of the structures shown in Fig. 2, is that in these the $G(x)$ block can be much simpler than the $F(x)$ device itself. This is possible as a result of the selection of expressions for the functions $r_{1}, r_{2}, \ldots, r_{m-1}, r_{m}$ [25]. The functions $g_{1}, g_{2}, \ldots, g_{m-1}, g_{m}$ are obtained through the functions $r_{1}, r_{2}, \ldots$, $r_{m-1}, r_{m}$ according to the formula $g_{i}=f_{i} \oplus r_{i}$. Each $r_{i}$ function can be selected arbitrarily, regardless of what the $f_{i}$ and $g_{i}$. functions are. The complexity of the $g_{i}$ function implementation depends on the selected variant of the $r_{i}$ function. At the same time, there is no dependence between the $g_{i}$ and $r_{i}$ functions with different $i$ indexes.

Synthesis of the DSF unit and the CED circuit. The simplest way to calculate $r_{i}$ functions is to assign them the values of input variables. This actually makes it possible not to synthesize the $R(x)$ block, but to implement it as a switch of input signals. The implementation of the $G(x)$ block itself depends on the chosen method of the $r_{1}, r_{2}, \ldots, r_{m-1}, r_{m}$ functions implementing.

The structures shown in Fig. 1 include a set of standard functional elements and blocks $F(x)$ and $F^{*}(x)$. The synthesis process consists in the CED circuit design. In it, the $H(f)$ block is known and is determined only by the selected $\Sigma_{m}$-code. It is necessary to synthesize the $H(x)$ block. This block is a combinational circuit for which the values of the $h_{1}, h_{2}, \ldots, h_{k-1}, h_{k}$ functions are uniquely determined on each input set $x_{1}, x_{2}, \ldots, x_{t-1}, x_{t}$. In practice, the $H(x)$ block structure is obtained by $h_{1}, h_{2}, \ldots, h_{k-1}, h_{k}$ functions system optimizing by standard optimization methods [31].

In the structures shown in Fig. 2, it is also necessary to synthesize the $G(x)$ block. The way to get the $g_{1}, g_{2}, \ldots, g_{m-1}, g_{m}$ functions is to use one of the input variables as $r_{1}, r_{2}, \ldots, r_{m-1}, r_{m}$ functions for all $f_{i}$ functions.

A 1 g o r i t m 1 .

1. Consistently consider the functions of the $F(x) f_{i}(i \in\{1,2, \ldots, m\})$ block outputs.

2. Suppose $i=1$.

3. Sequentially select the values of the function of the correction variable $r_{j}=x_{j}(j \in\{1,2, \ldots, t\})$.

4. Suppose $j=1$. 
5. Calculate the complement functions for each of the outputs of the block $F(x) f_{i}: g_{i, j}=f_{i} \oplus r_{j}(i \in\{1,2, \ldots, m\})$.

6. Optimize the $g_{i, j}$ functions (at this stage, it is possible to optimize the functions as a system), which makes it possible to synthesize the $G(x)$ block in the selected element basis.

The research results indicate that for each output of the $G(x)$ block, the $x_{1}$, $x_{2}, \ldots, x_{t-1}, x_{t}$ variable, which gives the simplest implementation of the corresponding function, can be selected.

A 1 g o r i t m 2 .

1. Consistently consider the functions of the $F(x) f_{i}(i \in\{1,2, \ldots, m\})$ block outputs.

2. Suppose $i=1$.

3. Sequentially select the values of the function of the correction variable $r_{j}=x_{j}(j \in\{1,2, \ldots, t\})$.

4. Suppose $j=1$.

5. Calculate the complement function $g_{i, j}=f_{i} \oplus r_{j}$.

6. Optimize the $g_{i, j}$ function.

7. Suppose $j:=j+1$.

8. Check if the final input variable reaches the condition $j>t$. If not, then go back to step 5 of this algorithm, otherwise go to step 9 .

9. Suppose $i:=i+1$.

10. Check the fulfillment of the condition for reaching the final function of the output of the $F(x)$ block $i>m$. If not, then go back to step 3 of this algorithm, otherwise go to step 11 .

11. For each $g_{i, j}$ function, select the input variable, the correction by which provides the least implementation complexity in the selected elemental basis.

12. Synthesize the block of realization of the system of $G_{1}(x)$ functions of complements and its copy $G_{2}(x)$.

Any arbitrary functions can be selected as $r_{1}, r_{2}, \ldots, r_{m-1}, r_{m}$ functions, it makes it possible to reduce the complexity of the technical implementation of each function and choose the most effective solution. This increases the number of ways to synthesize the fault-tolerant devices. Examples of using the presented methods for the $G(x)$ block synthesizing are similar to those considered in [25].

Experiments with combinational benchmarks. The use of the $\Sigma_{m}$-codes to calculations checking by one of the blocks in structures with double modular redundancy and in structures obtained on the basis of Boolean complement should have an impact on reducing the complexity indicators of the tech- 


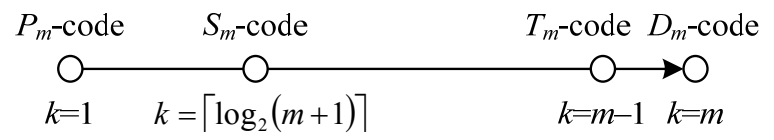

Fig. 3. Redundancy scheme of various sum codes

nical implementation of final fault-tolerant devices. At the same time, the selected code will also determine the set of error diagnostics objects identified at the outputs (their multiplicities and types) and, ultimately, determine the correcting ability of structures synthesized on their basis.

The literature describes in detail the methods for the fault-tolerant devices synthesizing based on typical modules ${ }^{1}$, as well as structures, for the check of which a code with the summation of weighted transitions from one bit to another with a sequence of weight coefficients forming a natural series of numbers $\left(T_{m}\right.$-code) [32], and a classical code parity $\left(P_{m}\right.$-code) [25] are used. Both codes have different error detection characteristics: the $T_{m}$-code detects any errors, except for errors with a maximum $d=m$ multiplicity, and the $P_{m-}$ code detects any errors with odd multiplicities, but any errors with even multiplicities, on the contrary, are not detected.

Both codes make it possible to synthesize typical CED circuits and can be applied in practice. When using the $T_{m}$-code to cover $100 \%$ of errors at the outputs of the diagnostic object, it is necessary to exclude the occurrence of errors with a maximum $d=m$ multiplicity [30]. To achieve the same property when using a $P_{m}$-code, it is necessary to exclude the occurrence of errors with even multiplicity (in practice, as a rule, for $100 \%$ error detection by the parity code, groups of independent outputs are monitored [2]).

An interesting case is the application of the classical Berger code $\left(S_{m^{-}}\right.$ code), which has $k=\left\lceil\log _{2}(m+1)\right\rceil$ check bits, for the calculations checking [29]. It detects any unidirectional and asymmetrical (multidirectional errors with an unequal number of distortions 0 and 1) errors in data vectors, which is used for monitoring devices with $100 \%$ error coverage for groups of unidirectionally independent and unidirectionally-asymmetrically independent outputs $[33,34]$. By their redundancy, the considered codes are in the sequence indicated in Fig. 3. There are other ways of constructing sum codes with other features of error detection [13, 14].

Let's consider the results of experiments with combinational benchmarks from the sets LG'91 и MCNC Benchmarks $[35,36]$, in which fault-tolerant devices were synthesized by $T_{m^{-}}, P_{m^{-}}$and $S_{m}$-codes. The purpose of the experiments is to evaluate the indicators of the structural redundancy of the fault-

\footnotetext{
${ }^{1}$ Modules with triple and double redundancy can be built using codes with repetition, $D_{m^{-}}$ codes.
} 
tolerant device in comparison with the fault-tolerant device obtained by the traditional structure with triple modular redundancy (TMR structure).

The experimental results for the five combinational benchmarks "dc1", "rd53", "p82", "m1" and "max512" are given in two types of tables. Table 1 (of the first type) shows data on the complexity of the technical implementation of the fault-tolerant device components in the conditional units of the library of functional elements stdcell2 2.genlib. It should be noted that during the experiments, the source check circuits $F(x)$ were not optimized (a complete device was selected). The $H(x), G(x)$ and $H^{*}(x)$ block structures were optimized using the simplify command in the SIS interpreter $[35,36]$. The rest of the faulttolerant device components are typical, consist of standard elements and are not optimized. Their complexities are estimated by the $L_{\geq 2}=136, L_{\mathrm{XOR}}=40, L_{\mathrm{AND}}=$ $=32, L_{q-\mathrm{OR}}=32+(q-2) 8$ values (in conventional library units).

During the experiments, fault-tolerant devices were synthesized according to the TMR-structure, for both structures with double modular redundancy and additional calculations checking by one of the DMR blocks, as well as for both structures using the Boolean complement principle. When synthesizing the fault-tolerant devices based on the Boolean complement method, an algorithm for check functions determining was used, which makes it possible to use one variable to correct the values of all outputs. The obtained indicators of the technical implementation complexity are presented in Tables 2-4 (of the second type). For each fault-tolerant device, not only absolute, but also relative values are given, namely, the proportion of the area occupied by the faulttolerant device on the chip from the area of the system with triple modular redundancy $(\mu, \%)$. In Tables $2-4$, two values are indicated for each circuit: above the line - the number of inputs, below the line - the number of outputs. Two numbers are given for each variant of the fault-tolerant device implementation: the absolute value of the indicator of the technical implementation complexity and the relative value, the share of the analytical indicator for TMR-structures.

The $T_{m}$-code using for calculations checking makes it possible to synthesize fault-tolerant devices that are simpler than when using TMR structures (see Table 2). Depending on the structure of the $F(x)$ source object, the gain when using the $T_{m}$-code is different. For example, for the "dc1" circuit, the gain is not so significant - up to $5 \%$ of the redundancy of the TMR structure. For the "rd53" and "p82" circuits, the improvement is $8-12 \%$. For the "m1" and "max 512 " circuits, the effect is even more noticeable - up to $20-24 \%$ of the redundancy of the TMR structure. It should be noted that two variants of the check circuit organization (check of $F(x)$ device and check of $G(x)$ device) give approximately the same gain in structural redundancy. The difference when using the same variable for correction is $1-2 \%$. 
Table 1. Indicators of the technical implementation complexity of the fault-tolerant devices components

\begin{tabular}{|c|c|c|c|c|c|c|c|c|}
\hline \multirow{2}{*}{$\begin{array}{l}\text { Bench- } \\
\text { mark }\end{array}$} & \multirow{2}{*}{$\begin{array}{c}\text { Inputs/ } \\
\text { Outputs } \\
\text { numbers }\end{array}$} & \multicolumn{7}{|r|}{ Area } \\
\hline & & $F(x)$ & $H(x)$ & $x_{1}$ & $x_{2}$ & $x_{3}$ & $x_{4}$ & $x_{5}$ \\
\hline \multicolumn{9}{|c|}{$G(x), T_{m}$-code } \\
\hline dc1 & $4 / 7$ & 976 & 488 & 608 & 576 & 712 & 672 & - \\
\hline rd53 & $5 / 3$ & 880 & 680 & 592 & 592 & 592 & 592 & 592 \\
\hline p82 & $5 / 14$ & 2368 & 1784 & 1976 & 1792 & 1920 & 1864 & 1848 \\
\hline $\mathrm{m} 1$ & $6 / 12$ & 3064 & 1296 & 1392 & 1560 & 1456 & 1856 & 1536 \\
\hline $\max 512$ & $9 / 6$ & 9632 & 5480 & 7832 & 6984 & 6456 & 6872 & 6696 \\
\hline \multicolumn{9}{|c|}{$G(x) \quad P_{m}$-code } \\
\hline \multicolumn{9}{|c|}{$H^{*}(x)$} \\
\hline $\mathrm{dc} 1$ & $4 / 7$ & 976 & 104 & $\underline{608}$ & $\underline{576}$ & 712 & 672 & - \\
\hline & & & & 88 & 160 & 112 & 216 & \\
\hline rd53 & $5 / 3$ & 880 & 528 & $\underline{592}$ & 592 & 592 & 592 & 592 \\
\hline 14 & נוכ & 000 & 320 & $\overline{408}$ & $\overline{408}$ & $\overline{408}$ & 488 & $\overline{488}$ \\
\hline p82 & $5 / 14$ & 2368 & 296 & 1976 & 1792 & 1920 & 1864 & $\underline{1848}$ \\
\hline & & & & 296 & 296 & 296 & 296 & 296 \\
\hline $\mathrm{m} 1$ & $6 / 12$ & 3064 & 208 & 1392 & $\underline{1560}$ & 1456 & 1856 & $\underline{1536}$ \\
\hline & & & & 240 & 240 & 240 & 240 & 240 \\
\hline $\max 512$ & $9 / 6$ & 9632 & 2512 & 7832 & 6984 & $\underline{6956}$ & $\underline{6872}$ & 6696 \\
\hline & & & & 2312 & 2312 & 2312 & 2312 & 2312 \\
\hline \multicolumn{9}{|c|}{$G(x) \quad S$-code } \\
\hline \multicolumn{9}{|c|}{$\overline{H^{*}(x)}, \mathrm{D}_{m}$} \\
\hline $\mathrm{dc} 1$ & $4 / 7$ & 976 & 368 & $\underline{608}$ & 576 & 712 & 672 & - \\
\hline & & & & $\overline{320}$ & $\overline{336}$ & $\overline{280}$ & $\overline{400}$ & \\
\hline $\mathrm{rd} 53$ & $5 / 3$ & 880 & 448 & $\underline{592}$ & $\underline{592}$ & $\underline{592}$ & $\underline{592}$ & $\underline{592}$ \\
\hline & & & & 464 & 464 & 464 & 520 & 520 \\
\hline p82 & $5 / 14$ & 2368 & 720 & $\underline{1976}$ & 1792 & 1920 & 1864 & 1848 \\
\hline & & 2500 & 120 & 664 & 648 & 712 & 744 & 696 \\
\hline $\mathrm{m} 1$ & $6 / 12$ & 3064 & 368 & 1392 & $\underline{1560}$ & $\underline{1456}$ & $\underline{1856}$ & $\underline{1536}$ \\
\hline & & & & 432 & 4960 & 488 & 472 & 544 \\
\hline $\max 512$ & $9 / 6$ & 9632 & 4056 & 7832 & 6984 & 6456 & 6872 & $\underline{6696}$ \\
\hline & & & & 4392 & 4328 & 3856 & 4016 & 4272 \\
\hline
\end{tabular}




\begin{tabular}{|c|c|c|c|c|c|c|c|}
\hline \multicolumn{8}{|c|}{ conv. unit } \\
\hline \multirow{2}{*}{$x_{6}$} & \multirow{2}{*}{$x_{7}$} & \multirow{2}{*}{$x_{8}$} & \multirow{2}{*}{$x_{9}$} & \multirow{2}{*}{$H^{*}(x)$} & \multicolumn{3}{|c|}{ Overhead elements } \\
\hline & & & & & TMR & DMR & $\mathrm{BC}$ \\
\hline \multicolumn{8}{|c|}{$G(x), T_{m}$-code } \\
\hline- & - & - & - & 584 & 952 & 1336 & 1616 \\
\hline- & - & - & - & 680 & 408 & 536 & 656 \\
\hline- & - & - & - & 1784 & 408 & 536 & 656 \\
\hline 1832 & - & - & - & 1408 & 1632 & 2336 & 2816 \\
\hline 7104 & 8352 & 9376 & 10192 & 5232 & 816 & 1136 & 1376 \\
\hline \multirow{2}{*}{\multicolumn{8}{|c|}{$\frac{G(x)}{H^{*}(x)}, P_{m}$-code }} \\
\hline & & & & & & & \\
\hline - & - & - & - & - & 3880 & 1064 & 1344 \\
\hline - & - & - & - & - & 3048 & 456 & 576 \\
\hline - & - & - & - & - & 7512 & 2128 & 2688 \\
\hline$\frac{1832}{240}$ & - & - & - & - & 10824 & 1824 & 2304 \\
\hline 7104 & 8352 & 9376 & 10192 & - & 29712 & 912 & 1152 \\
\hline$\overline{2312}$ & $\overline{2312}$ & $\overline{2312}$ & $\overline{2312}$ & & 29112 & & \\
\hline \multirow{2}{*}{\multicolumn{8}{|c|}{$\frac{G(x)}{H^{*}(x)}, S_{m}$-code }} \\
\hline & & & & & & & \\
\hline - & - & - & - & - & 3880 & 1920 & 2200 \\
\hline - & - & - & - & - & 3048 & 664 & 784 \\
\hline- & - & - & - & - & 7512 & 4016 & 4576 \\
\hline$\frac{1832}{504}$ & - & - & - & - & 10824 & 3320 & 3800 \\
\hline 7104 & 8352 & 9376 & 10192 & - & 29712 & 1552 & 1792 \\
\hline$\overline{4376}$ & $\overline{4480}$ & $\overline{4624}$ & $\overline{4768}$ & - & & & \\
\hline
\end{tabular}


Table 2. Indicators of the technical implementation complexity of the fault-tolerant devices based on the Boolean complement by the $T_{m}$-code

\begin{tabular}{|c|c|c|c|c|c|c|c|c|c|c|c|}
\hline TMR & DMR & $\begin{array}{c}\text { Bench- } \\
\text { mark }\end{array}$ & $x_{1}$ & $x_{2}$ & $x_{3}$ & $x_{4}$ & $x_{5}$ & $x_{6}$ & $x_{7}$ & $x_{8}$ & $x_{9}$ \\
\hline \multirow{4}{*}{3880} & \multirow{3}{*}{3776} & $\begin{array}{c}\mathrm{dc} 1 \\
\underline{4}\end{array}$ & \multicolumn{9}{|c|}{$F(x)$} \\
\hline & & & $\frac{3688}{95,052}$ & $\frac{3656}{94,227}$ & $\frac{3792}{97,732}$ & $\frac{3752}{96,701}$ & - & - & - & - & - \\
\hline & & & \multicolumn{9}{|c|}{$G(x)$} \\
\hline & 97,32 & & $\frac{3784}{97,526}$ & $\frac{3752}{96,701}$ & $\frac{3888}{100,206}$ & $\frac{3848}{99,175}$ & - & - & - & - & - \\
\hline \multirow{4}{*}{3048} & \multirow{2}{*}{2976} & $\begin{array}{c}\mathrm{rd} 53 \\
\frac{5}{2}\end{array}$ & \multicolumn{9}{|c|}{$F(x)$} \\
\hline & & & $\frac{2808}{92,126}$ & $\frac{2808}{92,126}$ & $\frac{2808}{92,126}$ & $\frac{2808}{92,126}$ & $\frac{2808}{92,126}$ & - & - & - & - \\
\hline & \multirow{2}{*}{\multicolumn{2}{|c|}{97,638}} & \multicolumn{9}{|c|}{$G(x)$} \\
\hline & & & $\frac{2808}{92,126}$ & $\frac{2808}{92,126}$ & $\frac{2808}{92,126}$ & $\frac{2808}{92,126}$ & $\frac{2808}{92,126}$ & - & - & - & - \\
\hline \multirow{4}{*}{7512} & \multirow[t]{3}{*}{7056} & $\begin{array}{c}\mathrm{p} 82 \\
\underline{5} \\
14\end{array}$ & \multicolumn{9}{|c|}{$F(x)$} \\
\hline & & & $\frac{6784}{90,309}$ & $\frac{6600}{87,859}$ & $\frac{6728}{89,563}$ & $\frac{6672}{88,818}$ & $\frac{6656}{88,605}$ & - & - & - & - \\
\hline & & & & & & & $G(x)$ & & & & \\
\hline & 93,93 & & $\frac{6784}{90,309}$ & $\frac{6600}{87,859}$ & $\frac{6728}{89,563}$ & $\frac{6672}{88,818}$ & $\frac{6656}{88,605}$ & - & - & - & - \\
\hline \multirow{4}{*}{10824} & \multirow{3}{*}{9760} & $\begin{array}{c}\mathrm{m} 1 \\
\underline{6}\end{array}$ & \multicolumn{9}{|c|}{$F(x)$} \\
\hline & & & $\frac{8568}{79,157}$ & $\frac{8736}{80,71}$ & $\frac{8632}{79,749}$ & $\frac{9032}{83,444}$ & $\frac{8712}{80,488}$ & $\frac{9008}{83,222}$ & - & - & - \\
\hline & & & & & & & $G(x)$ & & & & \\
\hline & 90,17 & & $\frac{8680}{80,192}$ & $\frac{8848}{81,744}$ & $\frac{8744}{80,783}$ & $\frac{9144}{84,479}$ & $\frac{8824}{81,523}$ & $\frac{9120}{84,257}$ & - & - & - \\
\hline \multirow{4}{*}{29712} & \multirow{3}{*}{25880} & $\begin{array}{c}\max 512 \\
\frac{9}{6}\end{array}$ & \multicolumn{9}{|c|}{$F(x)$} \\
\hline & & & $\frac{24320}{81,852}$ & $\frac{23472}{78,998}$ & $\frac{22944}{77,221}$ & $\frac{23360}{78,621}$ & $\frac{23184}{78,029}$ & $\frac{23592}{79,402}$ & $\frac{24840}{83,603}$ & $\frac{25864}{87,049}$ & $\frac{26680}{89,795}$ \\
\hline & & & & & & & $G(x)$ & & & & \\
\hline & 87,103 & & $\frac{24072}{81,018}$ & $\frac{23224}{78,164}$ & $\frac{22696}{76,387}$ & $\frac{23112}{77,787}$ & $\frac{22936}{77,194}$ & $\frac{23344}{78,568}$ & $\frac{24592}{82,768}$ & $\frac{25616}{86,214}$ & $\frac{26432}{88,961}$ \\
\hline
\end{tabular}


Table 3. Indicators of the technical implementation complexity of the fault-tolerant devices based on the Boolean complement by the $\boldsymbol{P}_{\boldsymbol{m}}$-code

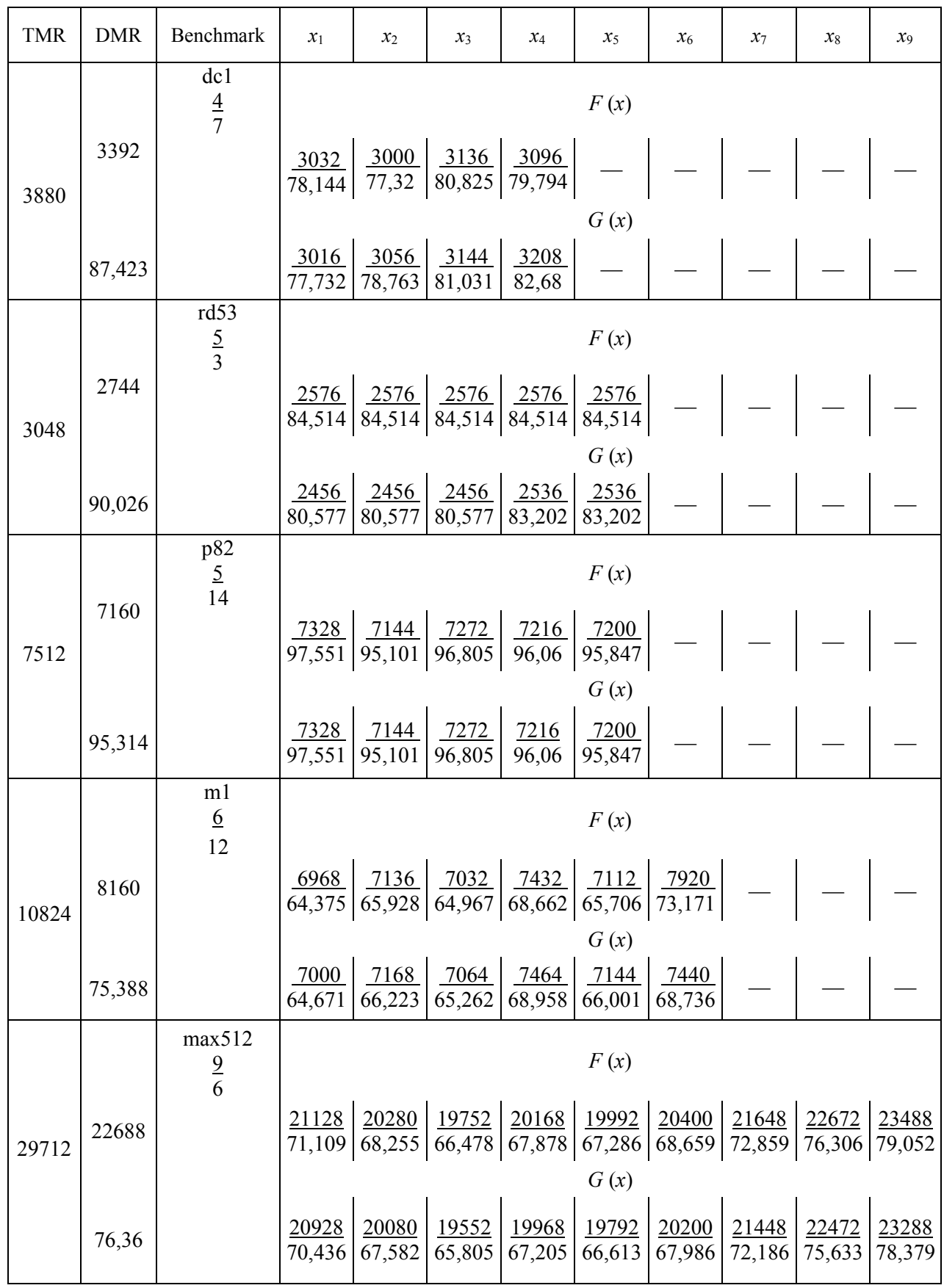


Table 4. Indicators of the technical implementation complexity of the fault-tolerant devices based on the Boolean complement by the $S_{m}$-code

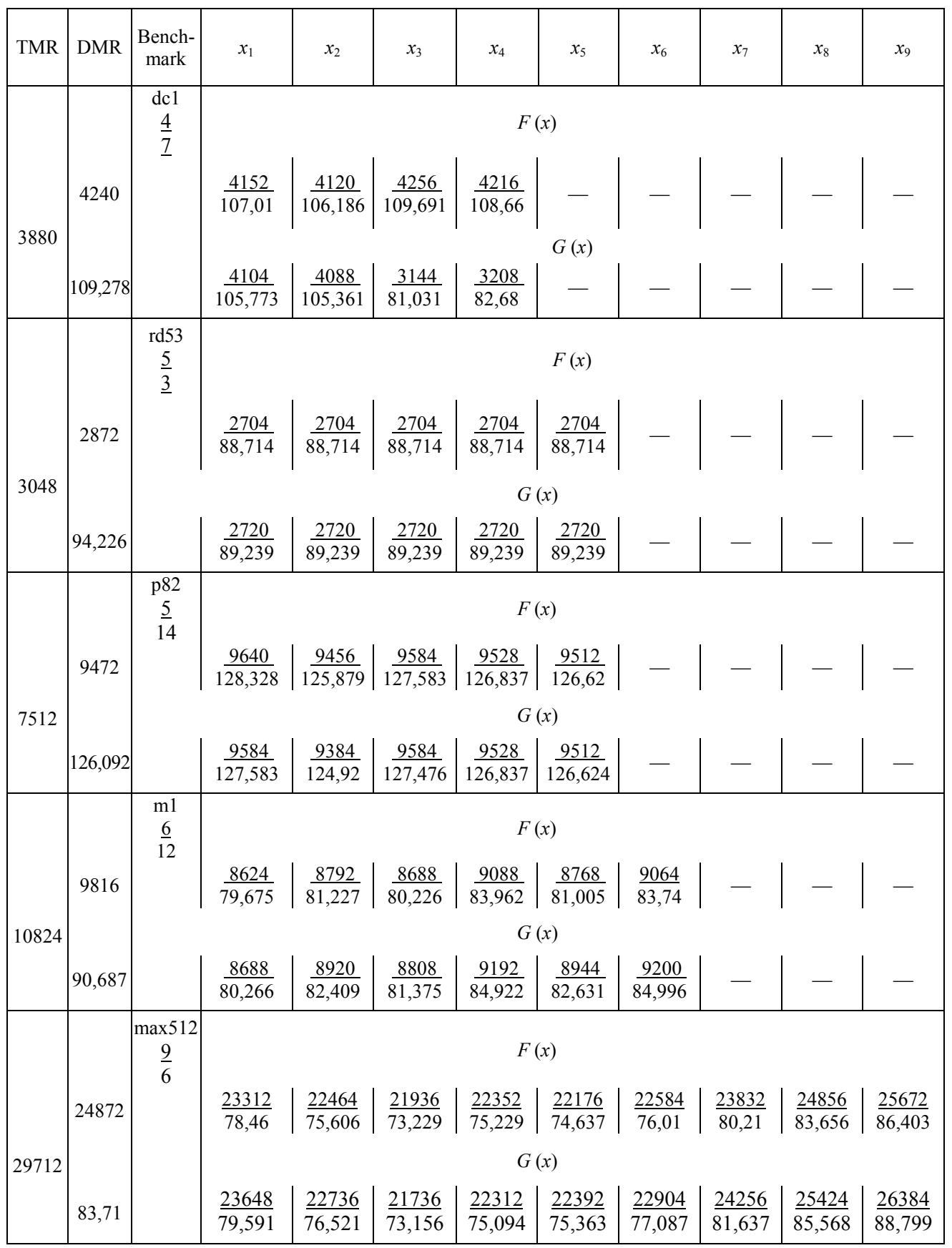


The $P_{m}$-code using for the check circuit organization gives a greater gain in the complexity of the technical implementation of the fault-tolerant device (see Table 3). For the "dc1" device, the technical implementation complexity is reduced by $23 \%$ compared to the TMR structure, for the "m1" and "max 512 " benchmarks it is reduced up to $36 \%$. However, for the "p82", the results are worse, the gain is $5 \%$ compared to the TMR-structure.

The $S_{m}$-code using for calculations checking also makes it possible to synthesize less redundant fault-tolerant devices than using the TMR-structure (see Table 4). For the "m1" and "max512", the improvement is $20-25 \%$, for the "rd53" it is $10-12 \%$. For the "dc1" and "p 82 ", the $S_{m}$-code using gives a significant deterioration compared to the use of the TMR-structure.

Thus, the use of each of the codes can lead to a reduction in the complexity of the technical implementation of the device. However, the $S_{m}$-code using is less effective compared to the $P_{m}$ - and $T_{m}$-codes using. First of all, this is due to the $S_{m}$-code features: its least significant bit is described by the function of the parity of all bits of the data vector, and the rest of the functions are not linear. It is clear that the $P_{m}$-code has advantages in this case. The $T_{m}$-code is constructed in such a way that to obtain its check bits in the encoder circuit, the same number of XOR elements is required as to obtain the parity function. Nevertheless, the check circuit by the $T_{m}$-code is more complicated.

In addition, for all the considered codes, such a variant of the check circuit organization can be chosen, which will ensure minimal structural redundancy of the fault-tolerant device. A greater effect can be achieved by choosing for each specific output its own variable (or even a function) for correction.

Each of the considered codes has its own features of error detection in data vectors:

- the $P_{m}$-code is effective for monitoring devices with independent outputs;

- the $S_{m}$-code is effective for monitoring devices with unidirectionally and asymmetrically independent outputs;

- the $T_{m}$-code is effective for monitoring devices at the outputs of which the occurrence of errors with $d=m$ multiplicities (devices with ( $m-1)$-independent outputs) is impossible $[13,14]$.

The results of experiments with combinational benchmarks indicate the effectiveness of using the proposed fault-tolerant devices and good prospects for their application in practice.

\section{Conclusions}

When synthesizing fault-tolerant digital computing devices and systems, approaches that are not based on the use of structures with modular redundancy can be used. One of such approaches is the application of a structure that uses a DSF unit based on Boolean complement with the calculations checking based 
on a pre-selected $\Sigma_{m}$-code. As the research results show, if the application of the principles of introducing modular redundancy in the fault-tolerant devices synthesis makes it possible to synthesize only one variant of its structure with fixed indicators of the technical implementation complexity, then the use of the Boolean complement method makes it possible to implement a large number of structures with different indicators of the technical implementation complexity. This makes it possible to design the fault-tolerant device with the least structural redundancy.

The devices for which the $P_{m}$-code is used in the CED circuit synthesis have the least technical implementation complexity, the more complex are those devices for which $T_{m}$-code is used in the CED circuit synthesis, and the most complex are those devices for which $S_{m}$-code is used in the CED circuit synthesis. However, these codes have different characteristics of detecting errors at the outputs of checked devices, this may be significant in practice. For each specific $F(x)$ device with a known structure, the most effective implementation should be chosen when considering various codes.

The disadvantage of all the considered approaches is the need to redefine the Boolean complement functions when considering a different number of methods for generating $r_{1}, r_{2}, \ldots, r_{m-1}, r_{m}$ correction functions. This requires obtaining logical expressions for the $g_{1}, g_{2}, \ldots, g_{m-1}, g_{m}$ Boolean complement functions on all combinations of $x_{1}, x_{2}, \ldots, x_{t-1}, x_{t}$ input variables. With a large value of $t(t>18 \ldots 20)$, optimization procedures can take a long time.

The considered approaches make it possible to obtain fault-tolerant devices and computing systems with the least technical implementation complexity in comparison with structures based on double and triple modular redundancy.

It is also necessary to note the following: the feature of the described fault-tolerant structures is that they are focused on working with single faults. However, in practice, in critical application systems, the input data changes quite rarely during their regular operation. In this case, conditions are created for the accumulation of hidden faults, which begin to manifest themselves when an emergency mode occurs. At the same time, multiple failures occur, which may not appear in the proposed fault-tolerant structures. Therefore, in further researches of the fault-tolerant structures synthesis methods, it is necessary to pay attention to the problem of the checkability of circuits when they function in the normal mode [37-39]. 


\section{REFERENCES}

1. Shcherbakov, N.S. (1975), Samokorrektiruyushchiesya diskretnye ustrojstva [Selfcorrecting discrete devices], Mashinostroenie, Moscow, USSR.

2. Sogomonyan, E.S. and Slabakov, E.V. (1989), Samoproverjaemyje ustrojstva i otkazoustojchivyje sistemy [Self-checking devices and failover systems], Radio i Svjaz, Moscow, USSR.

3. Sapozhnikov, V.V. and Sapozhnikov, Vl.V. (1992), Samoproveryaemye diskretnye ustrojstva [Self-checking discrete devices], Energoatomizdat, St. Petersburg, Russia.

4. Mikoni, S.V. (1992), Obshchie diagnosticheskie bazy znanij vychislitelnyh sistem [General Diagnostic Knowledge Base of Computing Systems], SPIIRAN, St. Petersburg, Russia.

5. Abramovici, M., Breuer, M.A. and Friedman, A.D. (1998), Digital System Testing and Testable Design, IEEE Press, New Jersey, USA.

6. Drozd, A.V., Kharchenko, V.S. and Antoshchuk, S.G. (2012), Rabochee diagnostirovanie bezopasnykh informatsionno-upravljayustchikh sistem [Objects and Methods of On-Line Testing for Safe Instrumentation and Control Systems], Natsionalnyy aerokosmicheskiy universitet «KhAI», Kharkov, Ukraine.

7. Hahanov, V. (2018), Cyber Physical Computing for IoT-driven Services, Springer International Publishing AG, New York, USA, DOI: 10.1007/978-3-319-54825-8.

8. Gavzov, D.V., Sapozhnikov, V.V. and Sapozhnikov, V1.V. (1994) "Methods for Providing Safety in Discrete Systems", Automation and Remote Control, Vol. 55, no. 8, pp. 10851122.

9. Sklyar, V.V. and Kharchenko, V.S. (2002), "Fault-Tolerant Computer-Aided Control Systems with Multiversion-Threshold Adaptation: Adaptation Methods, Reliability Estimation, and Choice of an Architecture", Automation and Remote Control, Vol. 63, no. 6, pp. 991-1003, DOI: 10/1023/A:1016130108770.

10. Bochkov, K.A., Harlap, S.N. and Sivko, B.V. (2016), "Development of fault-tolerant systems based on diversified bases", Avtomatika na transporte, Vol. 2, no. 1, pp. 47-64.

11. Fujiwara, E. (2006), Code Design for Dependable Systems: Theory and Practical Applications, John Wiley \& Sons, New Your, USA..

12. Sapozhnikov, V.V., Sapozhnikov, Vl.V. and Efanov, D.V. (2018), Kody Khemminga v sistemakh funktsionalnogo kontrolja [Hamming Codes in Concurrent Error Detection Systems of Logic Devices], Nauka, St. Petersburg, Russia.

13. Sapozhnikov, V.V., Sapozhnikov, Vl.V. and Efanov, D.V. (2020), Kody s summirovaniem dlya sistem tekhnicheskogo diagnostirovaniya. Tom 1: Klassicheskie kody Bergera i ih modifikacii [Sum Codes for Technical Diagnostics Systems. Volume 1: Classical Berger Codes and Their Modifications], Nauka, Moscow, Russia.

14. Sapozhnikov, V.V., Sapozhnikov, Vl.V. and Efanov, D.V. (2021), Kody s summirovaniem dlya sistem tekhnicheskogo diagnostirovaniya. Tom 2: Vzveshennyje kody s summirovanijem [Sum Codes for Technical Diagnostics Systems. Volume 2: Weight-Based Sum Codes], Nauka, Moscow, Russia.

15. Gavrilov, M.A., Ostianu, V.M. and Potekhin, A.I. (1970), "Reliability of discrete systems”, Itogi nauki i tekhniki. Ser. "Teoriya veroyatnostej. Matematicheskaya statistika. Teoreticheskaya kibernetika», pp. 7-104.

16. Hamamatsu, M., Tsuchiya, T. and Kikuno, T. (2008), "Finding the Optimal Configuration of a Cascading TMR System", 14th IEEE Pacific Rim International Symposium on Dependable Computing, December 15-17, 2008, Taipei, Taiwan, pp. 329-350, DOI: 10.1109/ PRDC.2008.12. 
17. Matsumoto, K., Uehara, M. and Mori, H. (2010), "Evaluating the Fault Tolerance of Stateful TMR", 13th International Conference on Network-Based Information Systems, September 14-16, 2010, Takayama, Japan, pp. 332-336. DOI: 10.1109/NBiS.2010.86.

18. Kubátová, H. and Kohlík, M. (2012), "Reduction of Complex Safety Models Based on Markov Chains", 2012 IEEE 15th International Symposium on Design and Diagnostics of Electronic Circuits \& Systems (DDECS), April 18-20, 2012, Tallinn, Estonia. DOI: 10.1109/DDECS.2012.6219050.

19. Stempkovskij, A.L., Telpuhov, D.V., Zhukova, T.D., Gurov, S.I. and Solovyev, R.A. (2017), "Methods for the synthesis of fault-tolerant combinational CMOS circuits providing automatic error correction", Izvestiya YUFU. Tekhnicheskie nauki, Vol. 7, no. 192, pp. 197-210. DOI 10.23683 / 2311-3103-2017-7-197-210.

20. Borecký, J., Kohlík, M., Vít, P. and Kubátová, H. (2016), "Enhanced Duplication Method with TMR-Like Masking Abilities", 2016 Euromicro Conference on Digital System Design (DSD), August 31 - September 2, 2016, Limassol, Cyprus. DOI: 10.1109/DSD. 2016.91.

21. Sapozhnikov, V.V., Sapozhnikov, Vl.V. and Efanov, D.V. (2019), Osnovy teorii nadezhnosti $i$ tekhnicheskoj diagnostiki [Fundamentals of the theory of reliability and technical diagnostics], Lan, St. Petersburg, Russia.

22. Potemkin, I.S. (1988), Funkcionalnye uzly cifrovoj avtomatiki [Functional units of digital automation], Energoatomizdat, Moscow, USSR.

23. Sapozhnikov, V., Sapozhnikov, Vl. and Efanov, D. (2020), "Typical Signal Correction Structures Based on Duplication with the Integrated Control Circuit", Proceedings of 18th IEEE East-West Design \& Test Symposium (EWDTS'2020), Varna, Bulgaria, September 4-7, 2020, pp. 78 -87. DOI: 10.1109/EWDTS50664.2020.9224649.

24. Sapozhnikov, V.V., Sapozhnikov, Vl.V. and Efanov, D.V. (2020), "Structures of signal correction circuits based on double modular redundancy with computation control", Izvestiya vuzov. Priborostroenie, Vol. 63, no. 8, pp. 687-701. DOI: 10.17586/0021-34542020-63-8-687-701.

25. Sapozhnikov, V.V., Sapozhnikov, Vl.V. and Efanov, D.V. (2020), "Signal Correction Circuit for Combinational Automation Devices on the Basis of Boolean Complement with Control of Calculations by Parity", Informatika, Vol. 17, no. 2, pp. 71-85, available at: https://doi.org/10.37661/1816-0301-2020-17-2-71-85.

26. Goessel, M., Morozov, A.V., Sapozhnikov, V.V. and Sapozhnikov, V1.V. (2003) "Logic Complement, a New Method of Checking the Combinational Circuits", Automation and Remote Control, Vol. 1, no. 1, pp. 153-161.

27. Göessel, M., Ocheretny, V., Sogomonyan, E. and Marienfeld, D. (2008), New Methods of Concurrent Checking: Edition 1., Springer Science+Business Media B.V., Dordrecht, Netherlands.

28. Das, D.K., Roy, S.S., Dmitiriev, A., Morozov, A.,। and Gössel, M. (2012), "Constraint Don't Cares for Optimizing Designs for Concurrent Checking by 1-out-of-3 Codes", Proceedings of the 10th International Workshops on Boolean Problems, Freiberg, Germany, September, 2012, pp. 33-40.

29. Berger, J.M. (1961), "A Note on Error Detection Codes for Asymmetric Channels", Information and Control, Vol. 4, no. 1, pp. 68-73. DOI: 10.1016/S0019-9958(61) 80037-5.

30. Sapozhnikov, V.V., Sapozhnikov, Vl.V., Efanov, D.V. and Dmitriev, V.V. (2017), "New Structures of the Concurrent Error Detection Systems for Logic Circuits", Automation and Remote Control, Vol. 78, no. 2, pp. 300-312. DOI: 10.1134/S0005117917020096.

31. Zakrevskij, A., Pottosin, Yu. and Cheremisinova, L. (2009), Optimization in Boolean Space, TUT Press, Tallinn, Estonia. 
32. Efanov, D.V., Sapozhnikov, V.V. and Sapozhnikov, Vl.V. (2020), "Typical Structure of a Duplicate Error Correction Scheme with Code Control with Summation of Weighted Transitions", Elektronne modelyuvannya, Vol. 42, no. 5, pp. 38-50. DOI: 10.15407/ emodel. 42.05.038.

33. Efanov, D.V., Sapozhnikov, V.V. and Sapozhnikov, Vl.V. (2017), "Conditions for Detecting a Logical Element Fault in a Combination Device under Concurrent Checking Based on Berger's Code", Automation and Remote Control, Vol. 78, no. 5, pp. 891-901. DOI: 10.1134/S0005117917040113.

34. Efanov, D.V., Sapozhnikov, V.V. and Sapozhnikov, Vl.V. (2020), "Organization of a Fully Self-Checking Structure of a Combinational Device Based on Searching for Groups of Symmetrically Independent Outputs", Automatic Control and Computer Sciences, Vol. 54, no. 4, pp. 279-290. DOI: 10.3103/S0146411620040045.

35. Sentovich, E.M., Singh, K.J., Moon, C., Savoj, H., Brayton, R.K. and SangiovanniVincentelli, A. (1992), "Sequential Circuit Design Using Synthesis and Optimization", Proceedings IEEE International Conference on Computer Design: VLSI in Computers \& Processors, October 11-14, 1992, Cambridge, MA, USA, USA pp. 328-333. DOI: 10.1109/ ICCD.1992.276282.

36. E. M. Sentovich, K. J. Singh, L. Lavagno et al. (1992), SIS: A System for Sequential Circuit Synthesis, Electronics Research Laboratory, Department of Electrical Engineering and Computer Science, University of California, pp. 45.

37. Drozd, A., Kharchenko, V., Antoshchuk, S., Sulima, J. and Drozd, M. (2011), "Checkability of the Digital Components in Safety-Critical Systems: Problems and Solutions", Proceedings of 9th IEEE East-West Design \& Test Symposium (EWDTS'2011), Sevastopol, Ukraine, pp. 411-416. DOI: 10.1109/EWDTS.2011.6116606.

38. Drozd, A., Drozd, M., Martynyuk, O. and Kuznietsov, M. (2017), "Improving of a Circuit Checkability and Trustworthiness of Data Processing Results in LUT-based FPGA Components of Safety-Related Systems", CEUR Workshop Proceedings, Vol. 1844, pp. 654-661, available at: http://ceur-ws.org/Vol-1844/10000654.pdf.

39. Drozd, O., Perebeinos, I., Martynyuk, O., Zashcholkin, K., Ivanova, O. and Drozd, M. (2020), "Hidden Fault Analysis of FPGA Projects for Critical Applications", Proceedings of the IEEE International Conference on Advanced Trends in Radioelectronics, Telecommunications and Computer Engineering (TCSET), February 25-29, 2020, Lviv-Slavsko, Ukraine. DOI: 10.1109/TCSET49122.2020.235591.

Received 08.06.21

\section{Д.В. Сфанов \\ ВІДМОВОСТІЙКІ СТРУКТУРИ ЦИФРОВИХ ПРИСТРОЇВ НА ОСНОВІ ЛОГІЧНОГО ДОПОВНЕННЯ 3 КОНТРОЛЕМ ОБЧИСЛЕНЬ ЗА КОДАМИ З ПІДСУМОВУВАННЯМ}

Розглянуто побудови відмовостійких цифрових пристроїв і обчислювальних систем без використання модульної надлишковості. Для корекції сигналів застосовано спеціальний блок фіксації спотворених сигналів, схема вбудованого контролю за заздалегідь обраним надлишковим кодом, а також блок корекції сигналів. Блок фіксації спотворених сигналів реалізовано за методом логічного доповнення (ЛД), що дозволяє побудувати більшу кіль-кість таких блоків з різними показниками складності технічної реалізації. Синтез відмовостійкого пристрою запропонованим методом дає змогу побудувати схему вбудованого контролю як початкового пристрою, так і блока ЛД в структурі блока фіксації спотворених сигналів. Це дозволяє серед багатьох способів реалізації відмовостійких 
пристроїв запропонованим методом обрати такий, що дозволить створити пристрій 3 найменшою структурною надлишковістю. Для створення схем вбудованого контролю можна використовувати різні надлишкові коди, у тому числі класичні та модифіковані коди з підсумовуванням. Запропоновано алгоритми синтезу блока фіксації спотворених сигналів і блок ЛД. Наведено результати експериментальних досліджень контрольних комбінаційних пристроїв з відомих наборів LG'91 і MCNC Benchmarks. Показано можливості даного методу при побудові відмовостійких цифрових пристроїв та обчислювальних систем.

Ключ ч в і сл о в а: відмовостійкий цифровий пристрій, контроль обчислень, логічне доповнення, відмовостійки структури, подвійна модульна надлишковість.

DMITRY V. EFANOV, Doctor of Technical Sciences, Associate professor, Deputy General Director for Research and Development of LLC STC “Integrated Monitoring Systems", Professor at Higher School of Transport of Institute of Machinery, Materials, and Transport of St. Petersburg and Peter the Great St. Petersburg Polytechnic University, Professor at Automation, Remote Control and Telecommunication on Railway Transport of Russian University of Transport. Graduation: Emperor Alexander I St. Petersburg State Transport University, 2007. The specialist in the area of discrete mathematics, reliability and technical diagnostics of discrete systems, synthesis of fault-tolerant and safety control systems, methods of monitoring transport systems. 